AperTO - Archivio Istituzionale Open Access dell'Università di Torino

\title{
Biomaterials for Total Joint Replacements
}

\section{This is a pre print version of the following article:}

Original Citation:

\section{Availability:}

This version is available http://hdl.handle.net/2318/1622868

since 2017-01-27T12:26:23Z

Publisher:

Springer-Verlag

Published version:

DOI:10.1007/978-1-84882-664-9

Terms of use:

Open Access

Anyone can freely access the full text of works made available as "Open Access". Works made available under a Creative Commons license can be used according to the terms and conditions of said license. Use of all other works requires consent of the right holder (author or publisher) if not exempted from copyright protection by the applicable law. 


\section{Metadata of the chapter that will be visualized online}

\begin{tabular}{|c|c|c|}
\hline Chapter Title & \multicolumn{2}{|c|}{ Biomaterials for Total Joint Replacements } \\
\hline Copyright Year & \multicolumn{2}{|c|}{2016} \\
\hline Copyright Holder & \multicolumn{2}{|l|}{ Springer-Verlag London } \\
\hline \multirow[t]{9}{*}{ Corresponding Author } & Family Name & Brach del Prever \\
\hline & Particle & \\
\hline & Given Name & Elena $M$. \\
\hline & Suffix & \\
\hline & Division & $\begin{array}{l}\text { 1st Orthopaedic Clinic University of } \\
\text { Turin }\end{array}$ \\
\hline & Organization/University & Centro Traumatologico Ortopedico \\
\hline & City & $\mathrm{T} D$ \\
\hline & Country & Italy \\
\hline & Email & elena.brach@unito.it \\
\hline \multirow[t]{8}{*}{ Author } & Family Name & Costa \\
\hline & Particle & \\
\hline & Given Name & Luigi \\
\hline & Suffix & \\
\hline & Division & $\begin{array}{l}\text { Department of Moleculat } \\
\text { Biotechnology and Health Sciences }\end{array}$ \\
\hline & Organization/University & $\begin{array}{l}\text { Molequiler Imaging Center, University } \\
\text { of Tur } 2 \text {. }\end{array}$ \\
\hline & City & Torino \\
\hline & Country & Italy \\
\hline \multirow[t]{8}{*}{ Author } & Family Name & Piconi \\
\hline & Particle & \\
\hline & Given Name & Corrado \\
\hline & Suffix & \\
\hline & Division & Department of Clinical Orthopedics \\
\hline & Organization/University & Catholic University \\
\hline & City & Torm \\
\hline & Country & Italy \\
\hline
\end{tabular}




\section{Author's Proof}

\begin{tabular}{|c|c|c|}
\hline \multirow[t]{8}{*}{ Author } & Family Name & Baricco \\
\hline & Particle & \\
\hline & Given Name & Marcello \\
\hline & Suffix & \\
\hline & Division & $\begin{array}{l}\text { Laboratory of Metallurgy, Chemistry } \\
\text { Department }\end{array}$ \\
\hline & Organization/University & University of Turin \\
\hline & City & Torino \\
\hline & Country & Italy \\
\hline \multirow[t]{8}{*}{ Author } & Family Name & Massè \\
\hline & Particle & \\
\hline & Given Name & Alessandro \\
\hline & Suffix & \\
\hline & Division & $\begin{array}{l}\text { Department of Orthopaedics and } \\
\text { Traumatology }\end{array}$ \\
\hline & Organization/University & University of Turin \\
\hline & City & Torino \\
\hline & Country & Italy \\
\hline Abstract & \multicolumn{2}{|c|}{$\begin{array}{l}\text { The role of the chemical-physical characteristics of the prosthetic biomaterials } \\
\text { in the biomechanics of a total joint replacement is presented. The following } \\
\text { main biomaterials are discussed: (1) the ultra high molecular weight } \\
\text { polyethylene (UHMWPE): standard, cross linked, stabilized with vitamin } \\
\text { E; ( } 2 \text { ) the polymethylmethacrylate (PMMA): standard cement, cements } \\
\text { with low temperature polymerization, antibiotic-loaded cements; (3) the } \\
\text { ceramic materials: oxide ceramics (over all Alumina-Zirconia Composites) } \\
\text { as components of the artificial joint, and calcium phosphate ceramics as } \\
\text { osteoconductive coatings on metal alloy components; (4) the metallic materials: } \\
\text { stainless steel, alloys based on the Co-Cr system, Ti and its alloys. To know } \\
\text { how the biomaterial modifies its mechanical properties in accordance with } \\
\text { the manufacturing, sterilization, storage, handling, contact with- and reaction } \\
\text { to the patient's tissues and fluids is fundamental for the researchers and the } \\
\text { surgeons, allowing a successful implant. }\end{array}$} \\
\hline
\end{tabular}

Keywords (separated by " - ")

Total joint replacements - Joint replacement - Biomaterials for total joint replacement 


\title{
Author's Proof
}

\section{Biomaterials for Total Joint Replacements}

\author{
Elena M. Brach del Prever, Luigi Costa, \\ Corrado Piconi, Marcello Baricco, \\ and Alessandro Massè
}

The European Society for Biomaterials defines a biomaterial "a material that interacts with the biological systems to evaluate, treat, reinforce or replace a tissue, organ or function of the organism" and the biocompatibility "the ability of a material to perform with an appropriate host response in a specific application" [1]. Recently, a new concept of biocompatibility was suggested in relation with the new technologies [2] and the fourth generation of biomaterials, the so-called smart or biomimetic materials [3]. Biocompatibility of a biomaterials is tested by in vitro screening, in vivo testing and clinical monitoring; each step evaluates the biological response in different conditions. In vivo, few

E.M. Brach del Prever, MD $(\bowtie)$

1st Orthopaedic Clinic University of Turin,

Centro Traumatologico Ortopedico, Turin, Italy

e-mail: elena.brach@unito.it

L. Costa, $\mathrm{PhD}$

Department of Molecular Biotech on and Health

Sciences, Molecular Imaging Cen 2

University of Turin, Torino, Italy

C. Piconi, MSc

Department of Clinica Oropedics,

Catholic University, Trer, Italy

M. Baricco, $\mathrm{PhD}$

Laboratory of Metallurgy, Chemistry Department, University of Turin, Torino, Italy

\section{A. Massè, MD}

Department of Orthopaedics and Traumatology, University of Turin, Torino, Italy seconds after the implantation, the biomaterial is rapidly adsorbed by proteins, whose quantity and organisation depend on the characteristics of the biomaterial, such as chemical composition of the bulk and surface, surface geometry, chemical and physical properties and the properties of the proteins. The host cells contact the protein layer: in total joint replacements, bone cells ongrowing on the prosthetic surface determine an osseointegration, fibrous cells as fibrous fixation. The production of wear and degradation particles, inevitable in all TJR, determines a biological response defined as bioreactivity; its major determinants are the particle size, concentration, surface chemical composition, surface energy, surface charge, surface roughness, particle shape and nature of adsorbed proteins; genetics might be influent in determining the biological response. The wear particles activate macrophages and initiate the inflammatory cascade resulting in bone loss and reduced bone production, prosthetic loosening and eventual TJR failure. New therapeutic strategies try to diminish particle-associated periprosthetic inflammation modifying the monocyte/ macrophages migration and activation [4].

Some wear metal particles are able to accumulate in the periprosthetic tissues and enter in the bloodstream, and can be responsible for chromosomal aberrations and DNA damage, which may promote cancerogenesis. Genotoxicity or mutagenicity, and/or carcinogenicity were demonstrated in experimental studies with $\mathrm{CoCr}$ 


\section{Author's Proof}

alloys, in accordance with epidemiological studies concerning the association of exposure to chromate particles and the incidence of nasal and lung cancer. Nickel is demonstrated to be genotoxic in vitro and carcinogenetic in vivo (lung and ethmoidal bone). However, after an average of 13 years and up to 25 years of follow-up, no increased cancer risk in patients with conventional total hip replacements was demonstrated [5-7].

In some previously sensitised patients, abrasion and corrosion products could behave like haptens, and the complex may stimulate memorylymphocytes initiating an inflammatory process. In particular, metal particles can either act as haptens bindings to protein carriers, or as adjutants, forming insoluble complexes with the antigens, initiating an immune response. Hypersensitivity reactions have been reported to be more frequent with stainlesssteel or cobalt alloy than with titanium alloy; hypersensitivity to polymethylmethacrylate was found to be $50 \%$ in failed total hip implants.

The probability of developing a metal allergy seems to be higher post-operatively and the risk further increased when failed implants were compared with stable TJRs [8]

\section{Ultra High Molecular Weight Polyethylene (UHMWPE)}

A macromolecular chain of polyethylene (PE) can be represented by the following formula:

$$
\sim\left(\mathrm{CH}_{2}-\mathrm{CH}_{2}\right)_{\mathrm{n}} \sim
$$

There are many types of $\mathrm{PE}$, all characterised by the same structural unit, but with different lengths, different space arrangements and different chain imperfections. In total joint replacements, the Ultra High Molecular Weight Polyethylene (UHMWPE) is used because of its biocompatibility and excellent mechanical properties. UHMWPE is a high density PE (HDPE) with molecular mass more than 2.000.000 amu; it is a semi-crystalline polymer with a set of ordered regions (crystalline lamellae), where macromolecules are tightly packed and the density is at its highest, embedded in a disordered amorphous phase, where macromolecules are randomly arranged and orientated. Table 5.1 shows the required characteristics of Thopaedic UHMWPE according to ASTM F648. With an exception for the density (crystallinity degree is expressed as the percentage by weight of the crystalline regions present in the whole polymer), there are virtually no superior limits for the other characteristics. This means that UHMWPE can have different starting characteristics, whether chemical, physical or mechanical. It is worth mentioning that the determination of these characteristics is carried out on the original material, before processing and sterilisation [9-11].

\section{Processing}

The UHMWPE powder coming from the 110 Ziegler-Natta polymerisation plant is processed 111 by compression moulding and ram extrusion: 112 both techniques use high pressure and controlled 113 heating and cooling cycles, and do not signifi- 114 cantly modify chemical, physical and structural 115 characteristics of the starting polymer, with the 116 exception of crystallinity (which is normally 117 much higher in the pristine powder). Therefore 118 all prosthetic components, ready to be sterilised, 119 still retain all properties of the starting material.

Table 5.1 Requirements for UHMWPE fabricated forms, according to ASTM F 648

\begin{tabular}{|c|c|c|c|}
\hline Property (unit) & Test method & $\begin{array}{l}\text { Requirement for } \\
\text { type I (GUR 1020) }\end{array}$ & $\begin{array}{l}\text { Requirement for } \\
\text { type II (GUR 1050) }\end{array}$ \\
\hline Density $\left(\mathrm{g} / \mathrm{cm}^{3}\right)$ & ASTM D-792 & $0.927-0.944$ & $0.927-0.944$ \\
\hline Ash (mg/kg) (maximum) & & 125 & 125 \\
\hline Tensile strength (MPa) & ASTM D 638 & & \\
\hline Ultimate (minimum) & & 40 & 40 \\
\hline Yield (minimum) & & 21 & 19 \\
\hline Elongation $(\%)$ & ASTM D 638 & 380 & 340 \\
\hline Izod impact strength $\left(\mathrm{kJ} / \mathrm{m}^{2}\right)(\mathrm{min})$ & ASTM F 648-10 Annex A1 & 126 & 73 \\
\hline Charpy impact strength $\left(\mathrm{kJ} / \mathrm{m}^{2}\right)(\mathrm{min})$ & ISO/CD 11542/2.3 & 180 & 90 \\
\hline
\end{tabular}




\section{Author's Proof}

Fig. 5.1 The degradation of the UHMWPE induced by high energy radiation sterilization; in presence of oxygen, from the atmosphere, the process is called oxidation. Vitamin E is able to stabilize against oxidation

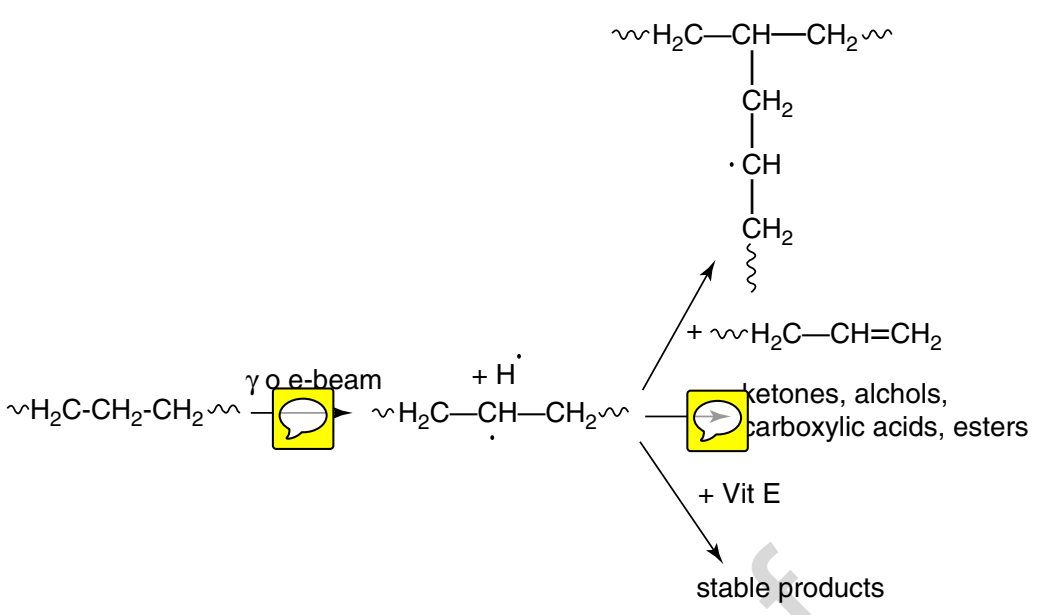

\section{Sterilisation}

The main sterilisation processes used nowadays employ ethylene oxide (EtO), gas-plasma (GP) and high-energy radiation (gamma radiation and electron beam) [9-11].

EtO and GP are surface sterilization methods and do not significantly affect the physical, chemical and mechanical properties of prosthetic components. GP is based on the action of ionized gas (i.e. hydrogen peroxide or peracetic acid).

Gamma radiations are emitted during decay of a ${ }^{60} \mathrm{Co}$ unstable nucleus. The dose absorbed by prosthetic components is about 25-30 kGy and depends upon the geometry of the sample and its position in relation with the source.

Electron beam is produced by thermally exciting a tungsten filament; the emitted electrons are accelerated by electric fields up to $10 \mathrm{MeV}$ and then conveyed onto the material to be sterilised. The advantages of this method are the easy control of the apparatus and the very short period of treatment (seconds).

\section{Degradation and Oxidation}

Gamma radiation and electron beam have a mean energy some orders of magnitude higher than that of polymeric chemical bonds and therefore generate the scission of some chemical bonds of the UHMWPE and formation of free radicals. If even a single C-C bond of the UHMWPE chain is broken and $2^{\circ} \mathrm{CH}_{2} \sim$ radicals are formed, the length of the chain and consequently the molecular mass decrease, with worsening of some chemical and physical material characteristics. This process is called degradation and in presence of oxygen, oxidation, which involves free radicals (Fig. 5.1).

The oxidative process depends on the radicals (formed during sterilisation) and on the amount of oxygen diffused into the PE components from the atmosphere during processing, sterilisation if conducted in presence of air and storage [12].

The distribution of oxidative products in the prosthetic component depends from the following variables: rate at which radiations is supplied, temperature of the sterilisation chamber, amount of oxygen present in the polymer when irradiated and diffused afterwards. Both in new and retrieved component, a crown effect or white band was the macroscopic evidence of this oxidation, responsible for many severe failures (delamination and fracture) during service in vivo in years '90'. Unfortunately, the first dramatic failures of UHMWPE components in the mid 1980s were attributed to inadequate mechanical properties of the UHMWPE, despite the evidence that these properties were much better than those required by ASTM F648.

\section{Packaging}

An adequate packaging of the components is mandatory to assure the correct atmosphere in accordance with the chosen sterilization process; the packaging could be critical when high energy 


\section{Author's Proof}

radiation in vacuum or inert gases to reduce oxidation is used. Currently employed packaging can be included in three categories [13]:

- Gas-permeable packaging, adequate for EtO and GP sterilization: a polyethylene terephthalate (PET) blister with a Tyvek® cover;

- Polymer barrier packaging: multi-layer plastic bags with gas-barrier properties with limited but measurable permeability to oxygen;

- Aluminium barrier packaging: virtually impermeable to gases.

Ultimately, a complete absence of oxidation is obtained only by gas-sterilisation.

\section{Debris and Diffusion}

Polyethylene debris are particles loss due to friction, caused by the reciprocal movement of the loaded articular surfaces: for equal mechanical stress, material and interface, abrasion is function of time. Whereas dramatic failures due to anomalous wear of heavily oxidised polyethylene have become quite uncommon nowadays, the production of abraded particles remains a problem in young patients whose life expectancy and quality of life are very high. The debris initiate an inflammatory reaction, the formation of a loosening membrane and a secondary osteolysis. The junctional tissue depends from number, size and chemical structures of UHMWPE debris. While pointing out that this topic is in continuous development, it is important to realise that the debris is not just simple UHMWPE particles, but biologically active particles whose surface interact with the human tissues according with their macro and micromorphology, contact area, molecules adsorpted on their surface, superficial hydrophilic and hydrophobic character, release of free radicals and time [9-11].

A process of adsorption and deep diffusion into the UHMWPE prosthetic components of organic molecules present in the synovial liquid, such as cholesterol, ester of cholesterol, squalene, $\beta$-carotene, takes place in vivo. This diffusion explains the yellowish colour in some retrieved components [14].

\section{Crosslinked UHMWPE}

To increase the abrasion resistance, crosslinked UHMWPE (X-PE) appeared on the market in the late 1990s [9-11, 15]. Crosslinking of a polymer is the linking of two or more molecular chains by means of chemical covalent bonds: macro radical species, formed by treatment with high energy, react with vinyl double bonds, linking the polymer chains with a $\mathrm{C}-\mathrm{C}$ stable chemical bond and giving Y-crosslink. The X-PE can be represented as one long, branched molecule with infinite molecular mass and consequent better wear resistance properties than standard UHMWPE, but also with some lower mechanical properties, owing to chemical and physical modifications induced by irradiation and heat treatment.

Commercially available X-PEs are obtained by different crosslinking processes, mainly based on gamma radiation or electron beam at doses ranging from 60 to $100 \mathrm{kGy}$ at room temperature or in the molten state, depending on the manufacturer; the residual radicals are eliminated by thermal treatment, sometime at temperature below the melting point of the polymer (typically at $130{ }^{\circ} \mathrm{C}$ ) (annealing). The final sterilization is obtained by EtO or gas-plasma or, in few cases, by gamma radiation in low oxygen environment [12].

Due to different crosslinking processes, the commercial X-PEs can be very different with variable properties, while standard UHMWPE has and maintain its properties if processed and sterilised in adequate ways.

Even if dramatic oxidation levels are not observed in newly produced UHMWPE components, it must be kept in mind that also very low oxidation levels can lead to significant variations in the mechanical properties of the polymer.

\section{Vitamin E Stabilised UHMWPE}

Vitamin E or, better, its synthetic derivative, alfatocopherol, is employed to stabilize UHMWPE against oxidation (ASTM F2695-12). As already pointed out, PE is easily subject to oxidation, which strongly compromises their mechanical properties. The oxidation is basically due to 


\section{Author's Proof}

the reaction between macroradicals and oxygen diffused into the polymer from the surrounding atmosphere; Vitamin E decreases the macro alkyl radicals available to react with the oxygen and thus to a significant slowdown of the oxidative cascade [9-11, 15-17]. Unfortunately, a decreased number of available alkyl radicals is also responsible for a lower efficiency of crosslinking at the same radiation dose, but a correct vitamin $\mathrm{E}$ concentration and radiation dose determine an oxidatively stable UHMWPE, without the need of a further thermal treatment, with enough crosslink density and consequent resistance to abrasion.

\section{Polymethylmethacrylate, the Orthopaedic Cement}

Orthopaedic cement is basically poly(methyl methacrylate) (PMMA) obtained by polymerising the methyl methacrylate monomer (MMA) $[18,19]$. Usually it is supplied in two separate packages: a brown coloured vial (in order to avoid any negative influence of the light on the monomer) containing about $20 \mathrm{ml}$ of transparent liquid, and one package or two containing $40 \mathrm{~g}$ of powder. The liquid contains: MMA, usually $\mathrm{N}, \mathrm{N}$ dimethyl-p-toluidine (DMPT) to accelerate the polymerisation process in presence of radicals, and traces of hydroquinone to avoid premature polymerisation of the monomer. The powder is formed by pre-synthesised PMMA (at times polymethylmethacrylate-styrene as copolymers are used), dibenzoyl peroxide (DBP) and barium sulphate (or zirconium dioxide), the latter may be supplied in a separate package. PMMA is in the shape of spherical particles having a variable diameter between 30 and $250 \mu \mathrm{m}$; the size of the particles determines the viscosity of the cement. When the contents of the two packages are mixed, DBP initiates the radical process of polymerisation through polymerisation accelerator and the effect of polymerisation heat. Barium sulphate makes the cement radio-opaque.

Cements produced by different industrial companies have different chemical-physical characteristics and mechanical properties due various components and their relative concentrations.
Bone cement preparation is characterised by 317 three phases: the wetting phase corresponds to 318 mixing the solid part with the liquid, the setting 319 phase (divided into 'dough time' and 'work- 320 ing time') corresponds to the initial polymeri- 321 sation process (about $5 \%$ of total), the curing 322 phase corresponds to the final hardening phase 323 and completion of the polymerisation process. 324 During mixing, benzoyl peroxide, present on 325 the surface of the PMMA powder, and DMPT 326 present in the liquid, interact and the polymeri- 327 sation process starts, mainly on the surface of 328 the pre-synthesised poly(methyl methacrylate). 329 Working time starts when a "dough" is obtained 330 which no longer sticks to gloves and tempera- 331 ture increase of the cement is minimal, corre- 332 sponding to minimal transformation of MMA to 333 PMMA. The final polymerisation phase is char- 334 acterised by the rapid increase of polymerisation 335 rate and temperature. The time required for the 336 various phases depend mainly on the tempera- 337 ture in the operating theatre: a $10{ }^{\circ} \mathrm{C}$ increase 338 causes polymerisation to start twice as quickly, 339 cutting mixing times by half. After polymeriza- 340 tion, less than $5 \%$ of MMA remains free and this 341 percentage may slowly spread into the body. The 342 MMA polymerization reaction is exothermic; the 343 high temperature favours DBP decomposition 344 leading to an increase in radical formation and 345 consequently an increase in polymerization pro- 346 cess. Therefore, polymerization speed is initially 347 minimal and gradually increases. Where process- 348 ing carried out in adiabatic conditions, the bone 349 cement temperature would reach $160{ }^{\circ} \mathrm{C}$. The 350 actual temperature reached by the cement dur- 351 ing the surgery depends on the balance between 352 quantity and speed with which the heat is pro- 353 duced, and how easily the heat is dispersed from 354 the surface into surrounding tissues. At the inter- 355 face with spongy bone, due to vascularisation 356 and the trabecular shape of the bone itself, tem- 357 peratures of $60{ }^{\circ} \mathrm{C}$ can be reached, while in the 358 centre of the mass of cement the temperature is 359 higher than $100{ }^{\circ} \mathrm{C}$. Schematically cement pro- 360 duces heat in function of the used amount, and 361 the temperature at the interface increases with the 362 higher quantity of cement. Based on this assump- 363 tion, an adequate surgical technique can lower 364 the temperature at the interface by using both 365 


\section{Author's Proof}

an adequate and not too thick layer of cement, and washing liquids in the final polymerization phase. Some cements are declared as "low temperature polymerization". They are characterised by a lower ratio monomer MMA/polymer that proportionally lowers the heat developed during transformation of monomer into polymer. High temperature is sought when the cement is used as adjuvant in bone tumours to ensure "sterilisation" of a bone surface from which the tumour has been removed; therefore in oncological surgery, standard PMMA is useful.

During polymerization reaction, a theoretical volumetric shrinking of the PMMA takes place proportional to the amount of MMA used; in the orthopaedic cement, the volumetric shrinking is $7 \%$ of the initial volume. Another characteristic of cement is the porosity due to $\mathrm{CO}_{2}$ formed during decomposition of the initiator, MMA monomer evaporation, air-bubble formed during hand preparation of the mixture, and the expansion due to temperature increase during polymerisation. In actual orthopaedic cements, the vacuum technique preparation decreases air-bubble formation; other factors cannot be eliminated.

Antibiotic-loaded cements are used in order to obtain a greater quantity of local antibiotic and to reduce the systemic quantity, thereby decreasing general toxicity; they are whether industrially packaged or prepared in the operating theatre according to the antibiogramme [20]. The state of the art on how the antibiotic manages to act is the following: the antibiotic, when soluble in water, dissolves from the surface of PMMA into the tissues; antibiotic molecules of notable size are physically blocked inside the bone cement and, therefore, cannot spread from inside the cement to the surface. The dissolution process depends on the type of antibiotic, on the characteristic of the surface of the cement and on the way the cement itself is prepared. When the antibiotic is added to the cement during preparation of the cement itself, that is in the operating room, only a small part of the antibiotic molecules are casually on the surface of the cement and will be able to dissolute. This process explains why the actual antibiotic-loaded cements have a limited antiseptical action.

\section{Ceramic Biomaterials}

Ceramics are solid materials, which have as their essential component inorganic non-metallic materials. In joint replacements oxide ceramics are used as components of the artificial joint (ball heads and inserts in hip replacements, femoral component in knee replacements, glenoid in shoulder replacements), while calcium phosphate ceramics (CPCs) are used as osteoconductive coatings on metal alloy components.

\section{Oxide Ceramics}

Two ceramic oxides are used in joint replacements: alumina and zirconia. Both are ionic solids, the high energy of the chemical bond giving them a high resistance to the corrosion, hardness, stiffness. The chemical stability of these oxides is the root of the excellent biological safety of their wear debris, a behaviour relevant for their intended use in arthroprostheses' bearings [21]. So far (end 2014) more that $80 \%$ of Total Hip Replacements (THR) in Italy, France, Germany and Austria are making use of ceramic ball heads, as well as in Japan and Korea, while in the USA ceramic ball heads are used in about $20 \%$ of THR only. The market leader CeramTec GmbH (Plochingen, Germany) declared to have sold by 2014 ten million of BIOLOX® ceramic bearing components. The behaviour of selected oxide ceramics is shown in Table 5.2.

\section{Alumina}

The development of alumina (aluminium oxide $\mathrm{Al}_{2} \mathrm{O}_{3}$ ) as a biomaterial began in the mid-60s, the behaviour of alumina components (say total hip replacement - THR ball heads) were improved continuously over more than 40 years of clinical use, making alumina one of the better characterised biomaterials [22]. The material used in biomedical application is $\alpha$-alumina, known as corundum, one of the most stable oxides, unaffected by corrosion (e.g. absence of ion release from bulk materials and from wear debris) in the most adverse conditions. The biocompatibility of alumina is a well-established property.

415
416
417
418
419
420
421
422
423

444 


\section{Author's Proof}

5 Biomaterials for Total Joint Replacements

t2.1

t2.2

t2.3

t2.4

t2.5

$\mathrm{t} 2.6$

t2.7

$\mathrm{t} 2.8$

t2.9

t2.10

$\mathrm{t} 2.11$

t2.12

t2.13

t2. 14

457

458

459

460

461

462

463

464

465

466

467

468

469

470

471

472

473

474

475

476

477

478

479

480

Table 5.2 Indicative values of selected properties of selected oxide bioceramics

\begin{tabular}{|c|c|c|c|c|}
\hline Properties (unit) & Unit & BIOLOX®forte & Prozyr® & BIOLOX®delta \\
\hline Usual name & & Alumina & $\begin{array}{l}\text { Zirconia } \\
\text { Y-TZP }\end{array}$ & $\begin{array}{l}\text { Alumina Matrix } \\
\text { Composite (AMC) }\end{array}$ \\
\hline Chemical composition & wt $\%$ & >99.8 Alpha-Alumina & $\begin{array}{l}\mathrm{ZrO}_{2}+5,1 \% \\
\mathrm{Y}_{2} \mathrm{O}_{3}\end{array}$ & $\begin{array}{l}\mathrm{Al}_{2} \mathrm{O}_{3}: 74 \\
\text { Y-TZP: } 24 \\
\text { Other oxides: } 2\end{array}$ \\
\hline Density & $\mathrm{g} / \mathrm{cm}^{3}$ & 3.97 & 6.08 & 4.37 \\
\hline Average grain size & $\mu \mathrm{m}$ & 1.75 & $<0.5$ & $\begin{array}{l}0.56\left(\mathrm{Al}_{2} \mathrm{O}_{3}\right) \\
0.15(\mathrm{Y}-\mathrm{TZP})\end{array}$ \\
\hline Bending strength & $\mathrm{MPa}$ & 630 & $>1500$ & 1390 \\
\hline Fracture toughness & $\mathrm{MPa} \mathrm{m}^{1 / 2}$ & 3.2 & 9 & 6.5 \\
\hline Elastic modulus & $\mathrm{GPa}$ & 407 & 200 & 358 \\
\hline Hardness & $\mathrm{HV}$ & 1975 & 1200 & 1760 \\
\hline
\end{tabular}

Notwithstanding the improvements introduced in the processing of alumina ceramics for clinical applications, the weak point of this alumina remains its low toughness that limits the flexibility in design of alumina components. For this reason, alumina components today are used in about $15-20 \%$ only of the ceramic implants, the balance being alumina-zirconia composites (see section on "Alumina-Zirconia Composites").

\section{Zirconia}

Zirconia (zirconium dioxide $-\mathrm{ZrO}_{2}$ ) ceramics were developed and introduced in clinical use in the late 80 s to overcome the toughness limitation of alumina. The early developments were oriented towards Magnesia-Partially Stabilised Zirconia (Mg-PSZ), in which the tetragonal phase is present within large cubic grains $(\varnothing 40 \div 50 \mu \mathrm{m})$ forming the matrix, a coarse structure that may negatively influence the wear properties of joints. Most of the developments were focused on Yttria stabilised Tetragonal Zirconia Polycrystal (YTZP), a ceramic constituted by tetragonal grains some hundreds of nanometer in size which has been a standard bearing material in orthopaedics up to the year 2000. The structural applications of zirconia ceramics are based on the constrained tetragonal-to-monoclinic $(\mathrm{t}-\mathrm{m})$ phase transformation, which acts as a dissipative mechanism for fracture energy. Briefly, the phase transformation is associated to the expansion of zirconia lattice (4 vol\% in free grains) and to its change in shape of the crystal cells that have to overcome the constraint of the matrix 489 grains. The process takes place at the expenses of 490 the elastic energy field (tensile) associated to the 491 developing crack, that to advance has in addition 492 to win the compressive stress field due to grain 493 $\mathrm{t}-\mathrm{m}$ transformation. At a macroscopic level, this 494 results in a toughened ceramic material, having 495 bending strength twice the one of alumina (900- 496 $1100 \mathrm{MPa}$ Vs. 500-600 MPa).

The $\mathrm{t}-\mathrm{m}$ phase transformation that gives to zirconia its interesting behaviour is also its main drawback: zirconia is a metastable material, and its clinical outcomes were contradictory [23]. The worldwide recall of the zirconia Prozyr ${ }^{\circledR}$ ball heads made by Saint Gobain Advanced Ceramics Desmarquest (Evreux, France) led to the practical abandon of zirconia in arthroplasty, where thus far it is still used in some niche products only. On the other hand, zirconia has found recently a wide field of application as a biomaterial in dentistry, for the construction of dental implants, and of the structure of crowns, bridges, dentures by CAD-CAM processing of presintered blanks [21].

Zirconia is also used as a coating obtained by in-situ oxidation of zirconium-2,5Nb alloy (Oxinium®, Smith \& Nephew, London, UK). In spite of many claims of good wear properties following total knee replacement either total hip replacement with OxZr femoral component, doubts have been recently raised about this technology in terms of wear reduction both in terms cost/benefits gains. Namely, due to its thickness 


\section{Author's Proof}

$(5 \mu \mathrm{m})$ the surface zirconia scale can be easily scratched by third bodies, leading to the increased wear of the polyethylene counterface [24].

\section{Alumina-Zirconia Composites}

The abandon of zirconia opened a technological gap in arthroplasty. Then, manufacturers focused their attention of alumina zirconia composites, especially on two classes of materials called Zirconia-Toughened Alumina (ZTA) when alumina is the main component and zirconia the balance, either Alumina-Toughened Zirconia (ATZ) when the main component is zirconia.

The first material of this class used in clinics is BIOLOX®delta (Ceramtec GmbH, Plochingen, Germany), which is formed by a matrix of chromia-doped alumina containing 17 vol\% Y-TZP and 1 vol\% of strontium zirconate platelets. For its peculiar microstructure, this material do not belong to any of the formerly described classes, and was identified as AMC: Alumina Matrix Composite. The finely and homogenous distribution of Y-TZP both of the platelets is obtained by nucleation within the alumina matrix during the sintering cycle.

The high bending strength and toughness of BIOLOX®delta in comparison with alumina and Y-TZP is due to the constrained $\mathrm{t}-\mathrm{m}$ transformation of the zirconia grains: the transformation imply the compressive deformation of the alumina matrix that has an elastic modulus (e.g. stiffness) twice the Y-TZP one (407 GPa Vs. $200 \mathrm{GPa}$ ). This increase the energy dissipated in the phase transformation. In addition, the platelets in BIOLOX®delta having width/length ratio 1:10 perform as a fibres reinforcing the material contributing to increase the material toughness. By December 2014 more than four million ball heads, inserts and condyles for knee replacements made out BIOLOX®delta have been sold worldwide, making this composite the standard "ceramic" in arthroplasty.

\section{Nitride Ceramics}

While titanium nitride (TiN) is clinical since a long while as a protective coating on metallic component of joint replacement bearings, bulk silicon nitride $\left(\mathrm{Si}_{3} \mathrm{~N}_{4}\right)$ has been tested for use in THR cups coupled to metallic either ceramic ball heads, but the future of this ceramic in arthroplasty remains still unclear [25].

\section{Complications with Ceramic Bearings}

Due to the improvements introduced in manufacturing, fractures of ceramic composites is today a very rare event. Arthroprostheses Registry data show that revision for fracture of ceramic component occurs with a frequency lower that the one of stem/neck fractures, either of collapse of the polyethylene inlays [26]. Fractures are typically associated to severe trauma either to technical errors in handling the ceramic components. Insert fractures are especially due to intraoperative mispositioning while the orientation of the cup is the reason of edge loading of the bearing components. Recently much attention was devoted to noises from THR bearings. Spectrum analysis demonstrated that the acoustical vibrations are depending on specific features of the implants. This explains also the prevalence of the problem in some Countries and its absence in others, likely due to the distribution of the devices [27].

\section{Calcium Phosphate Ceramics}

Calcium phosphate ceramics (CPCs) are since a long time used to give bone-bonding behaviour to the surfaces of metallic joint replacements (e.g. on THR stems) to enhance bony fixation. CPC osteoconductive coatings are a well established technology in joint replacements and long term follow-ups confirm the results obtained in early works [28]. CPC are a family of compound with different in vivo behaviour depending on a number of parameters especially on $\mathrm{Ca} / \mathrm{P}$ ratio the most stable being Hydroxyapatite $\mathrm{Ca}_{10}\left(\mathrm{PO}_{4}\right)_{6}(\mathrm{OH})_{2}$ [29].

Osteoconductive $\mathrm{CP}$ coatings are made by plasma spray. A critical aspect in this technology is the $\mathrm{Ca} / \mathrm{P}$ ratio of the starting powder and its crystallinity. Powder experience a severe 592 


\section{Author's Proof}

heating/cooling thermal cycle during this process. Formation of amorphous phases and of resorbable calcium phosphate ceramic (CPC) compounds, segregation of $\mathrm{CaO}$ and oxidation reactions must be carefully controlled. Namely, the rate of bone formation and the resorption of coating and its mechanical stability (shear strength, bond strength, fatigue life) are depending on a number of parameters, like e.g. presence of leachable phases, crystallinity, residual porosity [30].

\section{Metallic Materials for Joint Prosthesis}

Metallic materials with industrial relevance for joint prostheses belong to three main groups [31-36]: (i) stainless steel; (ii) alloys based on the Co-Cr system; (iii) $\mathrm{Ti}$ and its alloys. (i) The austenitic AISI 316 stainless steel was the first material used for orthopaedic implants. When it is specified as AISI $316 \mathrm{~L}$, the carbon content is limited to $0.03 \mathrm{wt} \%$ for improving the corrosion resistance of this material. (ii) $\mathrm{Co}-\mathrm{Cr}$ based alloys have been used for total joint prostheses since the early 1900s and are originating from modifications of dentistry alloy Vitallium (Haynes Stellite alloy N. 21). They combine good mechanical properties with a high biocompatibility, due to the presence of $\mathrm{Cr}$, which forms spontaneously a protective oxide layer. The carbon content in the alloy must be carefully controlled, because the formation of carbide phases may be detrimental for mechanical properties. (iii) $\mathrm{Ti}$ and Ti-based alloys are widely used as biomaterials for their high biocompatibility, mainly due to a high corrosion resistance related to the formation of a passive oxide layer at the surface. Good mechanical properties and low density constitute an additional benefit for joint prostheses production. Commercially pure $(\mathrm{cP}) \mathrm{Ti}$ is used in different grades, as a function of the oxygen content as impurity. Common Ti-based alloys contain aluminium (Al) and vanadium (V), the last often substituted by Niobium $(\mathrm{Nb})$ in order to increase biocompatibility. The main components and physical properties of most widely used metallic biomaterials for joint prosthesis are collected in Table 5.3.

The industrial production of metallic components for joint prosthesis may be carried out in different steps. As a first step, raw metals and alloys are processed into stock shapes, such as bars, sheet, rods, plates, tubes, wires and powders. The second processing step is used to tailor the microstructure of the alloy, which is strongly related to the mechanical properties of the implant, by means of thermo-mechanical treatments. The transformation of stock materials into final products may be obtained by investment casting, machining, forging, and sintering. Techniques used to manufacture various alloys to produce metallic biomaterials for joint prostheses are collected in Table 5.4. Surface coatings aimed to improve functional properties of implant (i.e. biocompatibility, bone fixation) are often added as a final step. Functionality and duration of implants in a physiological environment are very sensitive to surface properties, which may be considered the most important and selective aspect for joint prosthesis selection. Surface treatments are mainly aimed to increase hardness and strength of the surface layer, in order to improve the resistance to wear and corrosion.

Even if metallic biomaterials show good static mechanical properties, they may suffer significantly for fatigue failures [37]. Fatigue strength is defined as the highest periodic stress that does not initiate a failure of the material after a given number of cycles. For hip prostheses, an average of $2 \cdot 10^{6}$ stress cycles per year can be estimated, so that more than $10^{8}$ cycles may be applied during a lifetime. The applied stress for fatigue failures is in the elastic region of the static loading, so that fatigue strength is significantly lower than ultimate tensile strength. Metallic biomaterials have fatigue strengths in air generally well above the minimum required for joint prosthesis applications. Mechanical properties of most widely used metallic biomaterials for joint prostheses are collected in Table 5.3, together with those of cortical bones for comparison.

Total joint replacements are subjected to wear and abrasion so that the resistance against them is an important criterion for biomaterials. 
Author's Proof
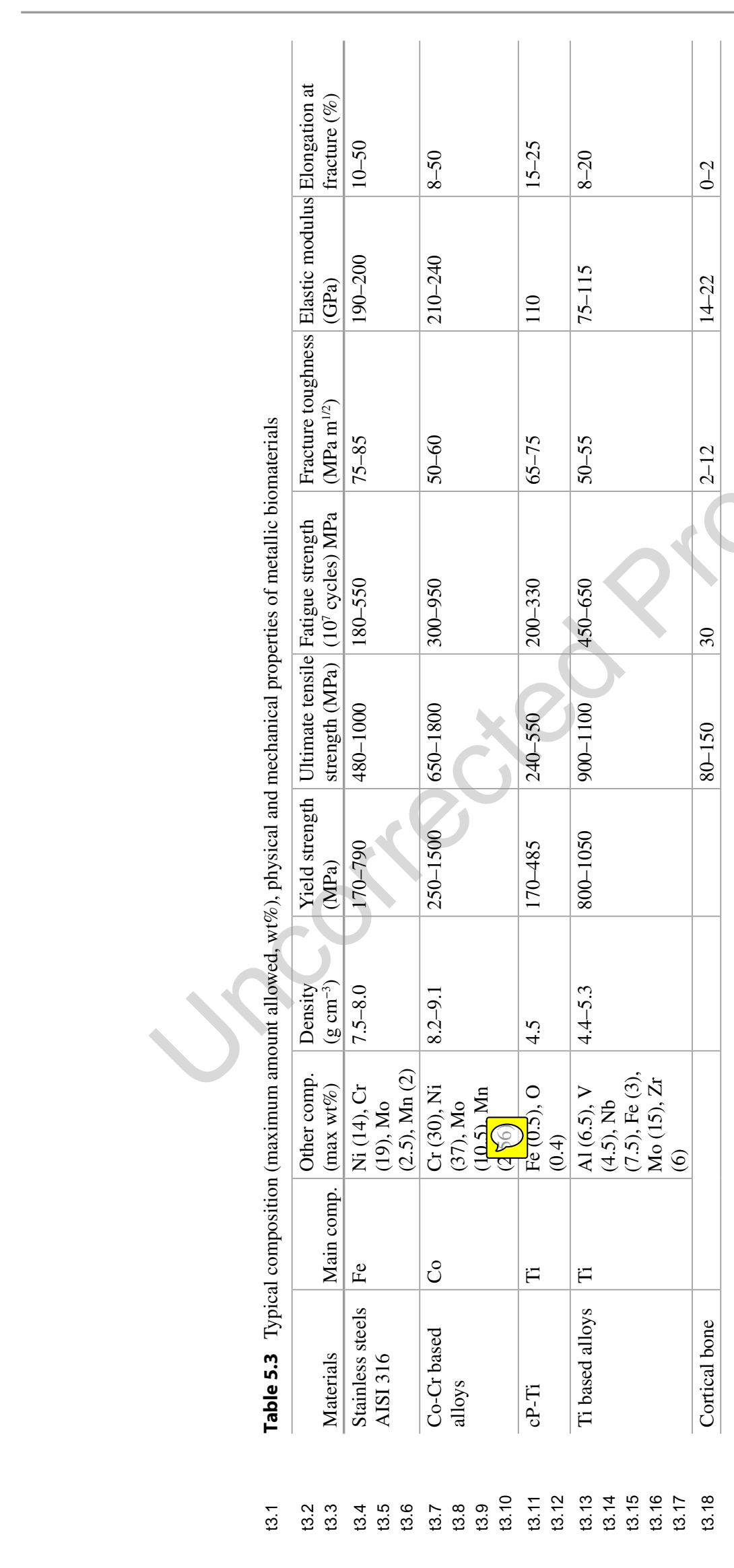


\section{Author's Proof}

5 Biomaterials for Total Joint Replacements

t4.1 Table 5.4 Techniques used to produce metallic biomaterials for total joint replacements

t4.2

t4. 3

\begin{tabular}{l|l|l|l|l}
\hline Technique & Stainless steels & Co-Cr based alloys & cP-Ti & Ti based alloys \\
\hline Casting & Not used & Investment casting & Difficult & Difficult \\
\hline Machining & Possible & Difficult & Possible & Possible \\
\hline Cold working & Rolling & Difficult & Rolling & Difficult \\
\hline Hot working & Wrought, forged & Wrought, forged & Not used & Wrought, forged \\
\hline Sintering & Possible & Hot isostatic pressing & Not used & Not used \\
\hline Thermal treatments & Recrystallisation & Precipitation hardening & Recrystallisation & Precipitation hardening \\
\hline
\end{tabular}

High carbon Co-Cr based alloys (F75) improve significantly mechanical properties after working, so that small plastic deformations at the surface significantly increase the hardness of the alloy and, as a consequence, its wear resistance. In addition, the presence of fine dispersed hard carbides increases the wear resistance of these alloys. Oxide films formed by passivation at the surface of the $\mathrm{Cr}$ and $\mathrm{Ti}$ containing alloys are generally resistant to abrasion [38]. Load required to fracture the oxide surface film is lower for Ti-based alloys with respect to $\mathrm{Co}-\mathrm{Cr}$ based alloy.

In conclusion, the ideal alloy should have the elastic modulus of bone, the strength of cobaltchromium alloys, the corrosion resistance and biocompatibility of titanium alloys, and the fabrication cost of stainless steels [35, 36]. Each material has advantages and disadvantages, which drive applications. Stainless steels have good corrosion and fatigue resistance in shortterm applications, have a low cost and they are easy to be machined, but tend to be corroded in long-term applications, have a high elastic modulus and can produce $\mathrm{Ni}$ and $\mathrm{Cr}$ allergy. $\mathrm{Co}-\mathrm{Cr}$ based alloys show long-term corrosion resistance, a high fatigue and wear resistance and a good biocompatibility, but they are difficult to machine, and thus expensive to process, and, like stainless steel, they suffer for a high elastic modulus and $\mathrm{Ni}$ and $\mathrm{Cr}$ allergy. Ti-based alloys have a low density, joined with a relatively low elastic modulus, show the greatest corrosion resistance and have an excellent biocompatibility, but they have a relatively low shear strength and wear resistance and are quite expensive. As far as concern the total hip replacement, Table 5.5 reports the types of bearing types implanted in Italy on 2014 [39].
Table 5.5 Types of total hip replacement bearings implanted in Italy on 2014

\begin{tabular}{l|l|r}
\hline Bearing type & \\
\hline Head & Cup & Share $(\%)$ \\
\hline Ceramic & Polyethylene & 50.7 \\
\hline Ceramic & Ceramic & 28.5 \\
\hline Metal & Polyethylene & 16.7 \\
\hline Metal & Metal & 2.8 \\
\hline Ceramic & Metal & 0.7 \\
\hline Metal & Ceramic & 0.5 \\
\hline Other & & 0.2 \\
\hline
\end{tabular}

Data from Torre et al. [39]

\section{References}

1. Williams DF. Definition in biomaterials. Proceedings of the consensus conference of the European Society for Biomaterials, Chester, 1986. Amsterdam: Elsevier Ed.; 1987. p. 49-59.

2. Mertz L. What is biocompatibility? A new definition based on the latest technology. IEEE Pulse. 2013;4:14-5.

3. Holzapfel BM, Reichert JC, Schantz JT, Gbureck U, Rackwitz L, Nöth U, Jakob F, Rudert M, Groll J, Hutmacher DW. How smart do biomaterials need to be? A translational science and clinical point of view. Adv Drug Deliv Rev. 2013;65:581-603.

4. Yao Z, Keeney M, Lin TH, Pajarinen J, Barcay K, Waters H, Egashira K, Yang F, Goodman S. Mutant monocyte chemoattractant protein 1 protein attenuates migration of and inflammatory cytokine release by macrophages exposed to orthopedic implant wear particles. J Biomed Mater Res A. 2014;102: 3291-7.

5. Visuri T, Pulkkinen P, Paavolainen P, Pukkala E. Cancer risk is not increased after conventional hip arthroplasty. Acta Orthop. 2010;81(1):77-81.

6. Visuri $\mathrm{T}$ Borg $\mathrm{H}$, Pulkkinen $\mathrm{P}$ Pavolainen $\mathrm{P}, 763$ Pukkala E. A retrospective comparative study of 764 mortality and causes of death among patients with 765 metal-on-metal and metal-on-polyethylene total hip 766 prostheses in primary osteoarthritis after a long- 767 term follow-up. BMC Musculoskelet Disord. 2010; 768 $11: 78$. 
7. Doherty AT, Howell RT, Bisbinas I, Learmonth ID, Newson R, Case CP. Increased chromosome translocations and aneuploidy in peripherial blood lymphocytes of patients having revision arthroplasty of the hip. J Bone Joint Surg Br. 2001;83B(7):1075-81.

8. Granchi D, Cenni E, Giunti A, Baldini N. Metal hypersensitivity testing in patients undergoing joint replacement: a systematic review. J Bone Joint Surg Br. 2012;94(8):1126-34.

9. Kurtz S. In: Kurtz S, editor. UHMWPE biomaterials hok. 3rd ed. New York: Academic; 2015. In www.UHMWPE.uni

11. Brach del Prever EM, Bistolfi A, Bracco P, Costa L. UHMWPE for arthroplasty: past or future? J Orthop Traumatol. 2009;10:1-8.

12. Bracco P, Brach del Prever E, Cannas $M$, et al. Oxidation behaviour in prosthetic UHMWPE components sterilised with high energy radiation in a low oxygen environment. Polym Degrad Stab. 2006;91:2030-8.

13. Costa L, Bracco P, Brach del Prever E, et al. A survey of oxidation and oxidation potential in contemporary packaging for polyethylene total joint replacement components. J Biomed Mater Res. 2006;78B(1): 20-6.

14. Costa L, Bracco P, Brach del Prever E, et al. Analysis of products diffused into UHMWPE prosthetic comonents in vivo. Biomaterials. 2001;22(4):307-15.

Josta L, Bracco P. Chapter 27: Mechanism of crosslinking and oxidative degradation and antioxidant stabilization of UHMWPE. In: Kurtz S, editor, UHMWPE biomaterials handbook. 3rd ed. New York: Academic; 2015. In press.

16. Wolf C, Lederer K, Bergmeister H, Losert U, Böck P. Animal experiments with ultra-high molecular weight polyethylene (UHMW-PE) stabilised with a-tocopherol used for articulating surfaces in joint endoprostheses. J Mater Sci Mater Med. $006 ; 17(12): 1341-7$

2 Kurtz S, Bracco P, Costa L. Chapter 17: Vitamin E-Blended UHMWPE Biomaterials. In: Kurtz S, editor. UHMWPE biomaterials handbook. 3rd ed. New York: Academic; 2015.

18. Wixon RL, Lautenschlager EP. Methyl methacrylate. In: Callagan JJ, Rosenberg AG, Rubash HE, editors. The adult hip. Philadelphia: Lippincott-Raven Pub.; 1998. p. 187-200.

19. Brach del Prever EM, Costa L, Baricco M, Piconi C, Massè A. Biomaterials for joint prosthesis. In: EFORT (European Federation of National Associations of Orthopaedics and Traumatology), editor. Surgical techniques in orthopaedics and traumatology. Paris: Elsevier; 2004.

20. Trippel SB. Antibiotic- impregnated cement in total joint arthroplasty. J Bone Joint Surg (A). 1986;68A:1297-302.

21. Piconi C, Condò SG, Kosmac T. Alumina- and zirconia-based ceramics for load bearing applications. In:
Shen JZ, Kosmac T, editors. Advanced ceramics for dentistry. 1st ed. Waltham: Butterworth-Heinemann; 2014. p. 220-53.

22. Piconi C. Alumina. In: Ducheyne P, Healey KE, Hutmacher DW, Grainger DW, Kirkpatrick CJ, editors. Comprehensive biomaterials, vol. 1. 1st ed. Amsterdam: Elsevier; 2011. p. 73-94.

23. Piconi C, Maccauro G, Angeloni M, Rossi B, Learmonth ID. Zirconia heads in perspective: a survey of zirconia outcomes in total hip replacement. Hip Int. 2007;17:119-30.

24. Piconi C, Porporati AA, Streicher RM. Ceramics in THR bearings: behavior in off-normal conditions. Key Eng Mater. 2015;631:1-7.

25. Piconi C. Non-oxide ceramics. Status quo in THR and future options. In: Cobb JP, editor. Modern trends in THA bearings. Berlin: Springer; 2010. p. 37-44.

26. Sadoghi P, Pawelka W, Liebensteiner MC, Williams A, Leithner A, Labek G. The incidence of implant fractures after total hip arthroplasty. Int Orthop. 2014;38:39-46.

27. Owen DH, Russell NC, Smith PN, Walter WL. An estimation of the incidence of squeaking and revision surgery for squeaking in ceramic-on-ceramic hip replacement. Bone Joint J. 2014;96-B:181-7.

28. Geesink RGT. Osteoconductive coatings for total joint arthroplasty. Clin Ortop. 2002;395:53-65.

29. Rey C, Combes C, Drouet C, Grossin D. Bioactive ceramics: physical chemistry. In: Ducheyne P, Healey KE, Hutmacher DW, Grainger DW, Kirkpatrick CJ, editors. Comprehensive biomaterials, vol. 1. 1st ed. Amsterdam: Elsevier; 2011. p. 187-221.

30. Sun L, Berndt C, Gross KA, Kukuc A. Material fundamentals and clinical performances of Plasma spray coatings: a review. J Biomed Mater Res (Appl Biomater). 2001;58:570-92.

31. Helsen JA, Breme HJ, editors. Metals as biomaterials. Chichester: Wiley; 1998.

32. Brunski JB. In: Biomaterials science, vol. 2. Academic P 1996. p. 37.

33. Gilbert JL. Metals. In: Callaghan JJ, Rosenberg AG, Rubash HE, editors. The adult hip, vol. 8. Philadelphia: Lippincott-Raven Publishers; 1998. p. 134.

34. Ashby MF. Materials selection in mechanical design. Oxford: Butterworth-Heinemann; 1999.

35. Chen Q, Thouas AG. Metallic implant biomaterials. Mater Sci Eng R. 2015;87:1-57.

36. Davies JR, editor. Metallic materials. In: Handbook of materials for medical devices. Materials Park: ASM International; 2003. p. 21-50.

37. Teoh SH. Fatigue of biomaterials: a review. Int J Fatigue. 2000;22:825-37.

38. Bolton $\mathrm{J}, \mathrm{Hu} \mathrm{X}$. In vitro corrosion testing of PVD coatings applied to a surgical grade Co-Cr-Mo alloy. J Mater Sci Mater Med. 2002;13:567-74.

39. Torre M, Luzi I, Carrani E, Leone L, Romanini E, Zanoli G. RIAP, Progetto Registro Italiano Artroprotesi - idea, sviluppo, avvio. Roma: Il Pensiero Scientifico; 2014. p. 144. 
